\title{
ТРАНСПОЗИЦИЯ В СФЕРЕ ЧАСТЕЙ РЕЧИ В МЕЖКАТЕГОРИАЛЬНОМ СИНТАКСИЧЕСКОМ ПЛАНЕ СЛОВА КАТЕГОРИИ СОСТОЯНИЯ В РУССКОМ ЯЗЫКЕ
}

\section{TRANSPOSITION IN THE SPHERE \\ OF PARTS OF SPEECH IN THE INTER \\ CATEGORICAL SYNTACTIC PLAN OF THE WORD CATEGORIES STATES IN THE RUSSIAN LANGUAGE}

\section{Xu Yuwei}

Summary: The article is devoted to the theory of transposition in the study of syntactic category of a special class of speech parts in the Russian language of the word state category. The author shows that when transposing words, the categories of States come from the noun, adjective, and adverb classes on-0. The concept of transposition in the sphere of parts of speech is considered either as transitivity, or as transposition, or as conversion, or as substitution. Besides, a multistage mechanism of transposition of words and word forms in the field of parts of speech, grammatical categories and lexico-grammatical level are considered as grammatical functioning of the Russian language and approach of lexical economy, which complicated modern grammar of the Russian language and have blurred boundaries, and the volume units of the same or different levels of language.

Keywords: theory of transposition; syntactic categories; morphological category; state category words, speech parts.
$\mathrm{T}$ еория транспозиции в сфере части речи остается весьма спорным вопросом, в процессах которого слова переходят из одной части в другую, при этом теория исследуется в работах А.А. Потебни, А.М. Пешковского, Л.В. Щербы, Ю.Д. Апресяна, О.М. Кима, А.Я. Баудера, О.С. Ахмановой, А.В. Бондарко, В.В. Бабайцевой, А.И. Смирницкого, В.Г. Гака, Е. Куриловича, Ш. Балли, Ф.С. Бацевич, Р.М. Гайсиной, Т.Г Рабенко, М.Ф. Лукина, О.Б Сиротининой и др.

Транспозиция грамматики как ветвь функциональной грамматики рассматривается учеными в настоящее время преимущественно А.В. Бондарко.

На этой базе общими задачами в сфере частеречной транспозиции на разных уровнях языка предполагаются в науке «определение сущности и назначения механизма транспозиции на уровне классов слов, характеристика эмиграционной и иммиграционной транспозиции слов применительно к каждой части речи, выявление причин возможности /невозможности тех или иных ти-

\author{
Сюй Юйвэй \\ Аспирант, Государственный институт русского языка \\ им. А.С. Пушкина \\ ixuyuwei@yandex.ru
}

Аннотация: Статья посвящена теории транспозиции при изучении синтаксической категории особенного класса частей речи в русском языке слова категории состояния. Автор показывает, что при транспозиции слова категории состояния происходят из классов существительного, прилагательного и наречия на -0. Понятие транспозиции в сфере частей речи рассматривается либо как переходность, либо как транспозиция, либо как конверсия, либо как субституция. К тому же, многоступенчатый механизм транспозиции слов и словоформ в сфере частей речи, грамматической категории и лексико-грамматических разрядов рассмотрен как грамматическое функционирование русского языка и подход лексической экономии, что осложняло современную грамматику русского языка и размыло границы и объем единиц одного и того же или разных уровней языка.

Ключевые слова: теория транспозиции; синтаксическая категория; морфологическая категория; слова категории состояния; часть речи.

пов частеречной транспозиции, анализ транспозиционных процессов в сфере частей речи в аспекте их односторонности / многосторонности, одноступенчатости / многоступенчатости, обратимости / необратимости и т.п., классификация частей речи с учетом теории транспозиционных явлений» [21, с. 47].

Касательно решения тех или иных видов перехода слов в частеречной системе, необходимо "выявление семантических и грамматических признаков категориальной переходной формы из одной части речи в другую, т.е. определение изменения в плане лексико-семантических, грамматических и синтаксических категорий, лексической и синтаксической дистрибуции, морфемной структуры и др. Кроме того, разработка критериев разграничения грамматических и лексико-грамматических параллелей той или иной части речи и установление ступеней частеречной транспозиционной словоформы, представленных, с одной стороны, типичными явлениями, обладающими полным набором дифференциальных 
признаков соответствующей части речи, а с другой синкретичными, промежуточными образованиями, в разной пропорции совмещающими свойства исходной и производной части речи имеют равный статус." $[19$, с. $7 ; 21$, с. $23 ; 20$, с. 35].

Касательно грамматических общностей слова категории состояния А.В. Исаченко трактует, что эти слова «по внешней форме совпадают либо с краткими прилагательными, либо с наречиями, фигурируют в функции сказуемого с аналитическими формами времени, семантически - некими состояниями» [7, с. 278].

По мнению В.В. Виноградова [4, с. 333], слова КС внешне отличаются от прилагательных и существительных отсутствием форм склонения и наличием форм времени с помощью связки, от наречий - формами времени и неспособностью качественно или обстоятельственно определять глагол и имя прилагательное. В этом отношении происходит изменение или утрата либо семантических, либо грамматических признаков на уровне одной части речи и переход классифицированных признаков другой части речи $[22$, с. $47 ; 3$, с. $135 ; 8$, с. 227 ; 9 , с. $100 ; 10$, с. 198].

Г.А. Золотова [6, с. 150] показывает 6 примерами разные омонимии "тепло":

1. Сонное тепло охватило его.

2. Жилище тепло и уютно.

3. Его встретили тепло.

4. В доме тепло.

5. Детям тепло.

6. Жить у бабушки было тепло и весело.

Следует заметить, что в 1) тепло представляется существительным ср.р. в качестве подлежащего, соответствующее роду и числу со сказуемым охватило; в 2) тепло в форме краткого прилагательного служит сказуемому, соответствующее роду и числу со подлежащим жилище; в 3) наречие тепло оформляет встретили с позиции ограничения действия; зато, Г.А. Золотова считает функцию слова тепло в 4), 5) и 6) не равными с словами тепло в предыдущих примерах.

Как О.М. Ким считает, что слова категории состояния формируются по транспозиции имен существительных и прилагательных [8, с. 227], в процессе которого лексического значения и синтаксической функции производного слова и производящей основы расходятся. В конце концов, слова переходят из одной части речи в другую.

Слова, производящие на -о в форме наречий и кратких прилагательных, типа тихо, радостно, весело, страшно, ясно, темно, ветрено, жарко, облачно, снежно, морозно и др. сохраняют явный признак качества; по происхождению они восходят к кратким прилагательным и являются их функциональными омонимами: пусто, весело, густо, просто, жалко, завидно и п. Употребляясь в функции главного члена безличного предложения и обозначая состояние, бывшие прилагательные теряют формы склонения и приобретают морфологическую неизменяемость, в лексическом значении которых имеется сема состояния как весело, грустно, страшно и др.

Кроме этих, еще немало "специальных" слов как фиолетово, которые представляются без значения состояния, остается возможностью сочетать с инфинитивом и управлять падежом, см. статью А.В. Циммерлинга: "в субнормативном русском языке класс предикативов, выражающих значение актуализованного признака и имеющих валентность на дат. п., не является полностью закрытым и пополняется такими предикатами как разг. Мне фиолетово, мне лениво, мне пополам, мне параллельно, ему пополам, ей стремно, москвичам очково и т.п." $[15$, с. 554; 14$]$.

При изучении синтаксической категории трудно определение синтаксической функции инфинитива в сочетании со словами на -о, которые по форме представляется применительно либо к словам категории состояния, кратким формам имен прилагательных и наречиям. Так как в предложении типа Жить у бабушки было тепло и весело слово на -о как весело рассмотрено либо как подлежащее, либо как сложное сказуемое с жить у бабушки. Насчет типов предложений либо рассматриваются как двусоставные или как безличные.

В этом отношении, автор работы полагает, что в двусоставном предложении при сочетании слова КС с инфинитивом и инфинитивным сочетанием, инфинитив и его словосочетание сквозь предметизацию рассмотрены как существительное или другие подлежащие среднего рода в предложение, в связи с этим, по поводу этимологического происхождения сказуемое представляется в форме ср. р., т.е. слова КС наследует синтаксическую функцию кратких прилагательных и описывают состояние делать что-либо.

В изъяснительных предложениях, как отмечают русисты, “синтез изъяснительных (субъектных и объектных) значений наблюдается при контактных словах, совмещающих категориальное значение кратких прилагательных и слова категории состояния на -о", см. Очень жалко, что он не придет; Хорошо, что ты со мной.

Наречие, как часть речи, зачисляет в группу, как А.А. Шахматов отметил, что "наречия, обозначающие как представления качествах-свойствах, так и представления об отношениях, мыслимых не атрибутивно, обстоятельственно" [18, с. 502].

Наречие перекрещивается с другими частями речи. 
И ярче и выразительнее всего размытость между наречиями и $\mathrm{KC}$.

Наречия и наречные слова морфологически является несклоняемыми по родам, числам и падежам, в отсутствии флексии, в способах обозначения степеней сравнения у слов на -о, для его сочетаемой формы еще "как в предлогах и союзах", ссылается из работы А.А. Потебни о наречиях: “Потеря склоняемости не связана в них с уничтожением специального значения, а есть только средство обозначения категории наречия" [12, с. 27]. В класс внутри наречия проходит переходность от качественно-относительных к предметно-обстоятельственным наречиям" [4, с. 292.] вызывает у нас внимание. Существует ряд слов КС, которые не имеют параллельных омонимов, ср. надо, можно, нельзя, боязно, надобно, невдомек и т.п. ср. также Мне невдомёк, Мне боязно в темноте. Таким образом, вследствие несогласуемости связочных слов, слова при переходе в разряд безличные предикативы утрачивают присущее им изначально значение и такие грамматические признаки, как формы падежей, рода, числа.

Слова как надо, можно, нужно, нельзя, которые в современном русском языке относятся либо к модельным словам, либо к предикативным наречиям, в общим нет определенной принадлежности в современном русском языке. Данные слова по поводу модальности и глагольности решительно не соответствуют признакам наречия. Кроме того, наречия "не могут быть предикативными", более того, "значение признака действия в них так сильно, что не может сочетаться с отвлеченностью связки" [11, с. 249]. В данной статье автор идеи считает их типичные слова категории состояния.

Более того, в группе слова имеют некоторые омонимические слова как существительные типа грех, мука, охота и др. Данные слова происходят из существительных, приобретая значение состояния вместо предметности существительных. Следует отметить, что слова, могущие превращаться в КС из существительных, принадлежат к числу отвлеченных существительных, которые в значительной степени передают значения ощущения и оценки внешнего мира, ср. рус. мука, лень, охота, досуг, пора, грех, срам, стыд и др. См. недосуг мне по магазинам ходить, неохота поесть, грех было подумать.

Кроме того, некоторые слова как рус. жалко, жаль, надо, подобно переходным глаголам, могут управлять винительным падежом, т.е. иметь при себе прямой объект, см. мне жаль его, ему жалко было себя, для этого надо десять рублей, надо хлеба. Эта черта опять-таки сближает слова разбираемого типа с глаголами. В предложениях с ними выражаются и субъект, и объект.

В морфологическом плане русские слова КС при помощи связки выражают следующие признаки: аналитические формы времени - время настоящего времени нулевой связкой, аналитические формы для прошедшего и будущего времени со связкой быть; аналитические формы вида при помощи связки как быть, стать, становиться и др. и аналитические формы наклонения.

В качестве темпорального распространителя предикативной основы предложения, глагольная связка является регулярным компонентом схемы. Форма настоящего времени без связки может быть рассмотрена в качестве имплицитного показателя категории времени, а формы будущего и прошлого времен - в качестве эксплицитного показателя времени. То же по отношению к категории наклонения: форма изъявительного наклонения имеет имплицитный показатель, а форма сослагательного наклонения - эксплицитный. С данной точки зрения мы тоже получаем подтверждения независимого статуса КС в части речи.

Характеризуя безличное предложение в синтаксической конструкции NDAT - (VLINK) - PRED [16, с. 72; 17, с. 627] слова КС употребляются в функции сказуемого безличного предложения с дательным падежом субъекта, ср. Мне холодно, Анне грустно, и в роли сказуемого двусоставного предложения с подлежащим-инфинитивом, например, Мне легко заниматься плаванием, Ему стыдно высказать свое мнение перед всеми. Можно сказать, что слова КС дативно-предикативной структуры образуют особый семантический класс, члены которого имеют синтактику, несовпадающую с употреблением глаголов и кратких прилагательных.

Таким образом, сильным фактом соотношения слова категории состояния с его параллельными частями речи показывается, что транспозиция как действующий механизм языка в грамматике представляется переходом из имен существительных, кратких форм имен прилагательных и наречия к группе слов категории состояния.

\section{ЛИТЕРАТУРА}

1. Ахманова 0.С. Словарь омонимов русского языка. Издание 3-е, стереотипное. М.: Русский язык. 1986.

2. Бабайцева В.В. Переходные конструкции в синтаксисе. Воронеж: Центрально-Черноземное книжное издательство. 1967.

3. Балли Ш. Общая лингвистика и вопросы французского языка. М.: Изд-во иностр. лит. 1955.

4. Виноградов В.В. Русский язык (грамматическое учение о слове). - М. 1972. 
5. Гак В.Г. Теоретическая грамматика французского языка : Учеб. для студентов вузов / В.Г. Гак. М.: Добросвет. 2000.

6. Золотова Г.А. «Синтаксический словарь русского языка» // Вопросы языкознания. 1980. № 4.

7. Исаченко А.В. Грамматический строй русского языка в сопоставлении со словацким. Морфология: в 2-х ч. Изд-е 2-е. Братислава: Изд-во Словацкой Академии наук. 1965. Ч. 1.

8. Ким 0.М. Транспозиция на уровне частей речи и явление омонимии в современном русском языке. Ташкент: Фан. 1978.

9. Лукин М.Ф. Трансформация частей речи в современном русском языке. Донецк: Изд-во Донецк. ун-та. 1973.

10. Мигирин В.Н. Очерки по теории процессов переходности в русском языке / Белорус, пед. ин-т. Бельцы, 1971.

11. Пешковский А.М. Русский синтаксис в научном освещении. - 8-е изд., доп. М.: Языки славянской культуры. 2001.

12. Потебня А.А. Из записок по русской грамматике: [Т. 1-2]. - Харьков: Д.Н. Полуехтов. 1888, вып. 1-2.

13. Смирницкий А.И. Так называемая конверсия и чередование звуков в английском языке // Иностр. яз. в шк. 1953. № 5.

14. Циммерлинг А.В. Внутри и снаружи: к типологии предикатов состояния // [Электронный ресурс] URL: https://www.academia.edu/18138229/Bнутри_и_ снаружи_к_типологии_предикатов_состояния_Inwards_vs_outwards_approaching_a_typology_of_stative_predicates_

15. Циммерлинг А.В. Именные предикативы и дативные предложения в европейских языках. // Компьютерная лингвистика и интеллектуальные технологии, вып. 9 (16) по материалам международной конференции «Диалог 2010». М.: РГГУ. 2010.

16. Циммерлинг А.В. История одной полемики. // Язык и речевая деятельность. №. 1. 1998.

17. Циммерлинг А.В. Типологический синтаксис скандинавских языков. М. Языки славянской культуры. 2002.

18. Шахматов А.А. Синтаксис русского языка. Л. 1927. вып. 2. Шигуров В.В. Сущность и основные типы транспозиции в русском языке // Функционально-семантические исследования: Межвуз. сб. науч. тр. Вып. 1 / Редкол.: Л. Л. Буланин (отв. ред.) и др. Саранск. 1996.

19. Шигуров В.В. Три этапа транспозиции глагола в наречие // Разноуровневые характеристики лексических единиц: Материалы межвуз. практ. конф:: В 3 ч. Ч. З. Смоленск. 1997.

20. Шигуров В.В. Функциональный и функционально-семантический типы транспозиции глагола в прилагательное // Функционирование языка в различных речевых жанрах: Материалы Всерос. науч. конф. Вып. 1. Ростов н/Д. 1997.

21. Шугуров В.В. Проспект транспозиционной грамматики современного русского языка. 1998.

\section{(c) Сюй Юйвэй (ixuyuwei@yandex.ru)}

Журнал «Современная наука: актуальные проблемы теории и практики»

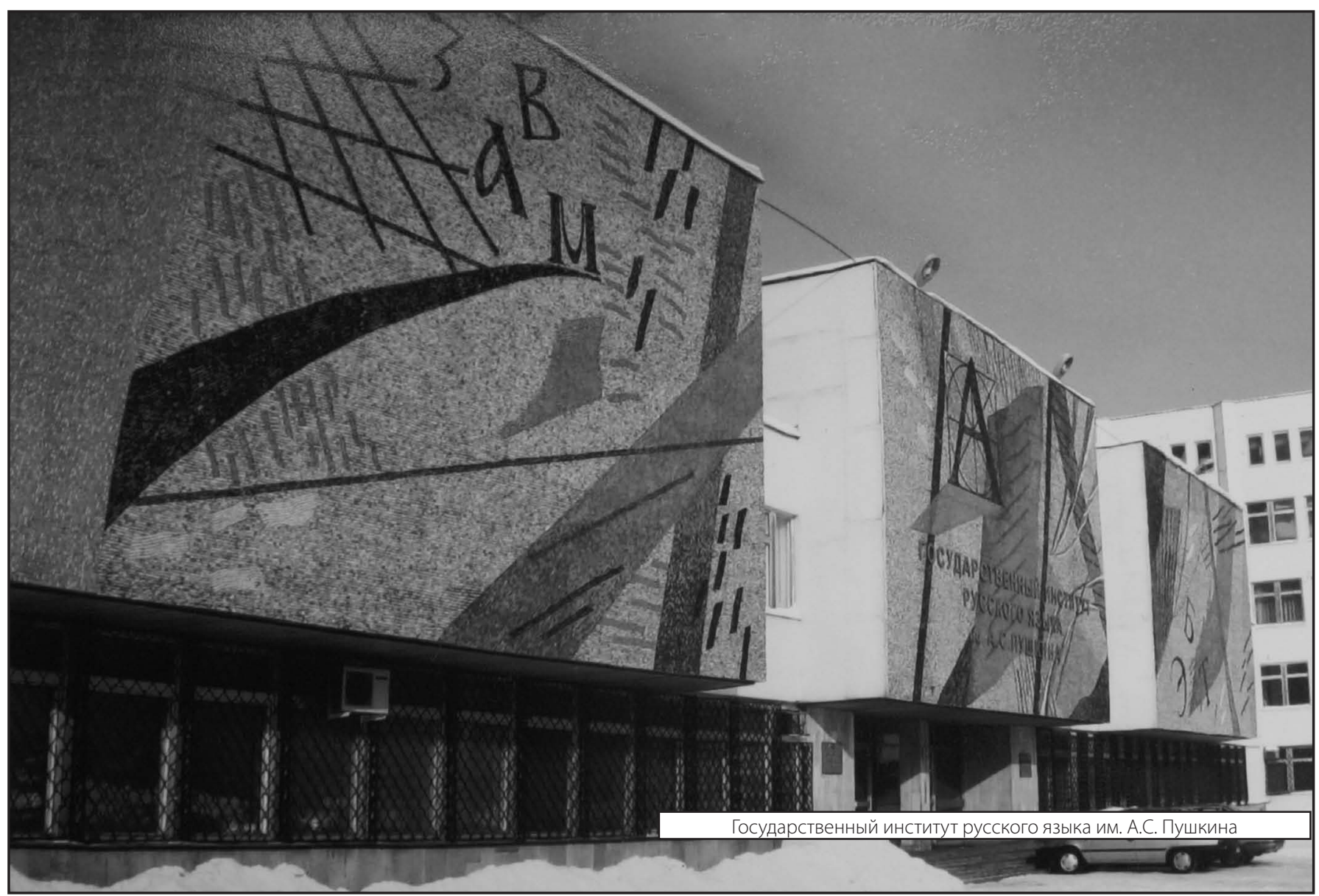

